\title{
Framing the benefits of higher education participation from the perspective of noncompleters
}

\section{Ian Cunninghame \& Tim Pitman}

This is an accepted manuscript version, which was published online 27 December 2019.

To cite this article: Ian Cunninghame \& Tim Pitman (2019): Framing the benefits of higher education participation from the perspective of non-completers, Higher Education Research \& Development, DOI: $\underline{10.1080 / 07294360.2019 .1705255}$

To link to this article: https://doi.org/10.1080/07294360.2019.1705255 



\title{
Framing the benefits of higher education participation from the perspective of non-completers
}

\author{
Ian Cunninghame and Tim Pitman \\ National Centre for Student Equity in Higher Education, Curtin University, Perth, Australia
}

\begin{abstract}
Ensuring that students of all backgrounds are smoothly transitioned through the stages of access, participation and completion in higher education has been the focus of much public policy and research in recent decades. Subsequently, public policy discourse treats those who do not complete their higher education degrees as unsuccessful, despite a lack of research considering the beneficial outcomes of non-completing students. Evidence of beneficial outcomes of higher education participation without completion has potential to challenge the deficit-centric discourse of completion dependent on a binary view of success and failure. This article details a critical discourse analysis of responses to a 2017 survey of university non-completers asked 'were there any benefits from the time you spent doing an [sic] incomplete degree?'. This study finds that noncompleters experience a wide range of benefits from incomplete studies despite the dominant discourse discounting their experiences as unsuccessful. Additionally, this study presents a critique of framing surveys of non-completing students within the normative bounds of success as completion in higher education, and instead calls for a more nuanced construction of success in higher education.
\end{abstract}

\section{Introduction}

Students who do not complete their degrees have always been a concern for higher education institutions, policymakers and educationalists (Pitman, 2014; Universities UK, 2016). Completion is often presented as 'an essential element of accomplishing the benefits of the undergraduate experience' (Higher Education Standards Panel, 2017, p. 11), and even more so as post-graduation success - at least as measured by employment - is seen as critical to reducing social inequality (Pitman, Roberts, Bennett, \& Richardson, 2019). Whilst they are not overshadowing goals of widening access and participation, outcomes relating to retention, completion and graduation are becoming important indicators of higher education's ability to provide lasting improvements to student equity (Meyer, St. John, Chankseliani, \& Uribe, 2013; Thomas, 2002). As a result, retention and completion are common research foci amongst higher education researchers. This is largely driven by an explicit long-term focus by successive governments internationally in order to improve outcomes for young people, particularly those from equity backgrounds (Bradley, Noonan, Nugent, \& Scales, 2008; Cahalan, Perna, The Pell Institute, \& PennAHEAD, 2015; Department for Education, 2017; Meyer et al., 2013).

Internationally, selected statistical government reporting indicates students from demographic groups historically underrepresented in higher education 
have lower rates of success and completion than the general student population (for e.g., Cahalan et al., 2015; Department of Education and Training, 2018; Universities, 2016). Such findings can lead educators and policymakers to form deficit discourses, that is, negative and counterproductive views about students from underrepresented backgrounds, consequentially leading to lower expectations of these students (Ford \& Grantham, 2003). Although governments have taken on recommendations to raise rates of retention and completion proportionate to participation, old concerns that more diverse student cohorts will reduce overall rates of completion persist (Ford \& Grantham, 2003; Pitman, Koshy, \& Phillimore, 2015), resulting in normative policy approaches to promoting retention and completion (Cribb \& Gewirtz, 2013). Interpretation of data underlying these reports often reveals 'deficit questioning' (Harper, 2012); for example asking 'why are completion rates for student group X so low?' rather than 'how have so many students from group $\mathrm{X}$ managed to complete despite the social, cultural, and economic barriers they experience?'. Approaching equity policy in the current way, potentially, risks replicating these social stratifications within higher education itself (Smit, 2012).

This article seeks to examine the extent to which framing success in higher education through limited dimensions of retention and completion may potentially be reliant on a deficit-based epistemological approach to achieving student equity in higher education. To do so, it must overcome the challenge of including the voices of those who have left higher education without completing a degree, as such cohorts are usually difficult to reach (Habel, Whitman, \& Stokes, 2016; Norton \& Cherastidtham, 2018). To this end, this article draws on data gathered through a 2017 Grattan Institute survey of 863 students who left their courses of study prior to completion and who responded to the request for information describing their truncated higher education experience (Norton \& Cherastidtham, 2018). By analysing students' own descriptions and explorations of their particular higher education experience, which many would frame as being 'unsuccessful', this article adds to the understanding that success is an amorphous term that students often view very differently (O'Shea \& Delahunty, 2018). This article seeks to answer the question: what can non-completers tell us about success in higher education?

\section{Research approach}

Considering the dearth of evidence pertaining to the benefits experienced by non-completing higher education students, this study sought deeper understanding of students' own conceptualisations of benefits resulting from their time at university. Past studies on the outcomes for students who do not 
complete have often focused on reasons for leaving their course of study and barriers to completion (see, for e.g., Marks, 2007; O'Keefe, Laven, \& Burgess, 2011), or have been ad-hoc investigations narrow in scope (see, for e.g., McCormack, 2005). Whilst these studies provide important perspectives on reducing the impact of non-completion, this study seeks to broaden the scope of conceptualising beneficial participation in higher education, and discerning the extent to which current survey structures can provide an holistic assessment of university non-completers' experiences.

The first part of this study consists of a qualitative analysis of open-ended survey responses from a survey conducted by the Grattan Institute as part of their report Dropping Out: the benefits and costs of trying university. The data obtained from the Grattan Institute's report was collected from an online survey run between 15 December 2017 and 5 January 2018, and promoted through social media (Norton \& Cherastidtham, 2018).

The second part of this study consists of a critical analysis of current policy and theoretical development evaluating university retention and completion. Policy discourse reviewed in this section of the article primarily relates to Australian higher education policy as the survey assessed in the first part of this study focuses on Australian non-completing students. Despite this focus, the subsequent analysis throughout this article will have broader implications for higher education policy internationally, as policy discourse in the UK and the US, for example, have long mirrored Australia's focus on widening participation and social mobility through higher education (see, for e.g., Department for Education, 2017; Liu, 2011; Reeves \& Howard, 2013). Discourse is considered in tandem with discussion of whether current survey development for assessing non-completion outcomes needs to be amended in order to accurately reflect the outcomes of university participation. Through consideration of the questions asked in the Grattan Institute survey, this article outlines considerations for future surveys of university non-completers.

\section{Research method}

Critical discourse analysis is the key methodological framework guiding the policy and survey data analysis undertaken for this study. This method of analysis is one which contends the context of language both presents and produces discourses of the workings of social structures through a process of interdiscursivity (Fairclough, 1993; Wodak, 2019), and also stipulates that meaning is communicated through the discourse of a text as a whole (Liu \& Guo, 2016; Wodak, 2019). As such, it is a particularly useful theoretical framework from which to assess the meaning conveyed through survey 
respondents' answers, and the limitations imposed upon them through the structures of the survey itself.

To assess the qualitative survey responses, unit level data was imported to NVivo 12 for coding. Subsequently, data for 953 participants was filtered to remove those who responded 'no' to the question of whether they had dropped out of a university degree in Australia. Further to this, respondent data for bachelor-degree leavers was isolated, resulting in 643 responses for analysis throughout this study. This was done in order to situate this work within the context of most work in completion and success research, considering undergraduate students are the primary focus of higher education policies concerning students.

Open-ended responses to the question 'Can you go into more detail about the benefits of starting the incomplete degree' were systematically coded via open and axial coding (Lockyer, 2004) to provide clear thematic categories for critically analysing the discourse present in students' responses. Responses were categorised via a word frequency analysis to identify common terms used in the open-ended responses, then were open coded according to the context for the use of these terms. These themes were then assessed for common themes indicating benefits of study that were not articulated within the existing options for benefits of study.

\section{Critical analysis of respondent discourse}

Of the 643 respondents who responded to Question 10 (Appendix B, Norton $\&$ Cherastidtham, 2018):

- $331(48.4 \%)$ indicated it was interesting

- $245(38.1 \%)$ indicated it taught them useful skills

- $211(32.8 \%)$ noted it helped clarify their career goals

- $182(28.3 \%)$ said they made lasting friendships or connections

- $99(15.4 \%)$ claimed their time at university provided no benefit

- $84(13.0 \%)$ indicated that attending university helped them get employed.

A word frequency query including stemmed words was run on responses to Question 11 (Appendix B, Norton \& Cherastidtham, 2018) from respondents who indicated some benefit from study in Question 10. Commonly used terms included core terms in the options for the previous question (helped, career, skills, interesting, friends and job); however, there are other frequently used words that indicate a broader set of benefits from study experienced by these respondents. Terms such as knowledge, learnings, studying, working, life, 
years, time and wanted, all refer to the breadth of university experiences beyond obtaining employable skills.

This informed a wider range of additional benefits articulated in the detailed responses, which were then coded for the following contextual categories:

- Time at university resulted in personal growth $(\mathrm{n}=232)$

- Time at university was a clarifying experience $(n=211)$

- Provided access to useful knowledge sources/structures ( $\mathrm{n}=171)$

- Experience of the university environment $(n=160)$

- Occupational skills development $(n=140)$

- Non-study extracurricular engagement $(n=90)$

- Provided experience of potential career pathways $(\mathrm{n}=54)$. Returned to study later ( $\mathrm{n}$ $=54$ )

- Used credits for another degree $(n=30)$.

The meanings present throughout these alternative categories were far more coherent than open responses sorted by the original options presented in question 10. There were limits to the extent that respondents' reflections provided accurate differentiation, as most tried to convey their experience through selecting one of the available options despite clear indications from open-ended responses that these options may have only been tangentially related to their further explanations. For example, those coded under 'provided experience of potential career pathways' might have selected 'clarified my career goals' or 'helped me get employed'.

Here it is worth reflecting on those respondents who selected 'no benefits' to the original survey option, as the nature of these responses highlight this point. Amongst the responses from those who indicated no benefit from study, the most common reason given in an open response was the cost of study. Though many spoke directly of financial cost of their incomplete study, particularly in terms of their $\mathrm{HECS}^{1}$ debt, a significant proportion of these responses were more concerned with the opportunity cost of studying at university. Many felt their studies were a 'waste of time and money' [\#8, \#135, \#222, \#387, \#656, \#855], but others were more specific. Some indicated that their incomplete studies actively prevented them from taking up opportunities and acted as an impediment to future employment. For example:

I didn't have any benefits, in fact, it has kept me from a couple of early career jobs until I removed it from my resume. I work as a Systems Engineer, and having an IT degree is almost completely useless. [\#243] 
What is interesting about this reflection is that it appears to directly contradict the experience of another respondent who studied humanities, and found it beneficial to communicate their participation without completion in higher education:

It gives me professional/social advantages [...] my subsequent employers have been impressed and hired me partially on the basis that I was admitted to my degrees, even though I didn't complete them. [\#456]

These responses communicate two things; firstly, that non-completion is not always a negative thing; and secondly, that effective reflection and communication of individuals' experiences of higher education can have material benefits.

Although 99 respondents selected 'no benefit' in their response to Question 10 , there were 58 respondents who provided further, detailed responses, and over a third of these (21) indicated some form of benefit from incomplete study. These responses were often indicative of their university participation being a clarifying experience, with some of these respondents selecting other options for benefits of study.

This emphasises a significant issue in the construction of surveys assessing noncompleters' perceptions of beneficial participation. Some of the respondents who selected 'no benefit', but who later articulated the benefits of their partial degree were possibly motivated to select 'no benefit' primarily due to negative associations with the result of their university experience - as expressed by concerns over their HECS debt and opportunity cost due to time spent studying - rather than a genuine lack of positive outcomes. Another possibility might be that the way the options were framed didn't reflect their experience of higher education, and thus they were disinclined to select those options. The following responses provide some examples of the variety of benefits expressed by those selecting 'no benefit':

It gave me confidence. [\#13]

It gave the opportunity to know that it wasn't the right time for me for uni but that I wanted to go back at some point. [\#457]

It was started as my parents thought I needed a degree, so I picked something I thought I might like. It was mostly business subjects, of which some were interesting \& I did learn quite a bit in the first year when doing economics \& statistics. [\#919]

The responses detailed above highlight potential inadequacy in the framing of the questions as it did not allow these non-completers to express the benefits that their participation in higher education provided. Alternate options ('it taught me useful skills', 'it helped clarify my career goals' and 'it was 
interesting') were likely too specific, or too vague for these respondents to feel they could select those options.

Respondents who indicated that their time at university was clarifying in some manner was the second-most commonly coded benefit of study amongst all participants in the survey. Though participants may have experienced some form of prompting due to the presence of the option 'it helped clarify my career goals', this did not mean that all respondents spoke of their career goals when encouraged to articulate their opinions.

For some, the benefit of clarifying the requirements of university-level study ensured that they had realistic expectations when re-engaging with higher education later in their life and, as such, were better prepared to study effectively:

It provided me with the understanding [sic] of the requirements of time and effort needed to undertake a degree, so when I enrolled in another degree I knew what I was getting myself into. [\#172]

As previously mentioned, there were many who provided detailed responses indicating the clarifying experience was directly related to career goals. Whilst career associated benefits of study presented some commonalities with partial completion as a clarifying experience, it was clear that this was not the most common expression of this benefit; instead, the most common crossover was with personal growth. These responses often indicated that at least part of the benefit of engaging with higher education, despite not completing it, was the fact that they came out with a better understanding of themselves and what their goals in life were:

What I found was that the skills and frameworks that I learned in my degree have allowed me a perspective on current events and all sorts of other things that I wouldn't have been equipped with otherwise. [\#129]

This response displays a sentiment commonly spoken of in the codings for personal growth: the notion that engaging in knowledge structures and research methods associated with academic study plays a crucial role in their personal growth. 118 respondents noted university provided access to useful knowledge, obtained lasting methods of accessing and assessing information, and embedded approaches to their lives and careers from a more considered perspective:

I've used frameworks I was introduced to at Uni to think about some of the problems I was exposed to in my previous career. Anthropology studies helped me approach parenting in a way that was more intuitive, in line with my values and in line with WHO recommendations. [\#820] 
Worth noting is the differentiation between 'useful knowledge' and 'occupational skills'. Though respondents were primed to consider work-based skills from the list of provided options, more respondents explicitly discussed knowledge gained than those who mentioned skills. Additionally, though many who discussed skills noted their application to employment, other respondents spoke of skills in the context of knowledge structures and analytic methods rather than skills more associated with occupational training:

Introduced to subject area of interest. Kept up academic skills. Practical knowledge of what is involved in that career. Part of lifelong learning [\#105]

This response provides an interesting example of this. The language used clearly delineates the occupational aspect of higher education, whilst identifying skills learnt were primarily of use as academic and learning skills. As a result, this respondent did not select 'it taught me useful skills' but did select 'it helped clarify my career goals', which might indicate an interpretation of the ordering and framing of options as mostly concerned with identifying occupational benefits.

There were small yet notable numbers of respondents who indicated their incomplete degree led eventually to completion of a different degree, either at the same or another institution. Some examples can be seen in the following responses:

It made me realise that I was entirely in the wrong field. I felt pressured to pursue a non-technical degree due to gendered expectations. Now I'm finally doing what I love. [\#125]

Arts degree a good grounding. Learned good skills useful in later return to study. Helped clarify direction that I was interested in through exposure to a broad range of subject areas. [\#291]

I started a double degree and dropped the humanities side of the double degree to chase further studies in science. I believe the humanities subjects I did helped to hone my writing skills and some of my humanities subjects also helped to further my understanding of my science studies because of overlapping topics. [\#936]

These responses display a number of beneficial aspects of non-completion of a degree, whilst also problematising the notion of non-completion representing failure or inability to complete university, given all three respondents eventually completed degrees. The ability to clarify their personal ambitions to pursue a degree despite societal expectations for \#125 combines the clarifying nature of HE participation with elements of personal growth, as well as useful knowledge and skill development. Respondent \#291 identifies the benefit of trying university, particularly through a non-specific degree, which is often disparaged for its lack of occupational application. Further to this, \#936 
reflects on their personal experience of drawing from the learnings of a dropped humanities double degree to improve their engagement and communication throughout their studies in science.

Many of these responses, along with those coded as finding university useful for skill development and engagement in tertiary knowledge structures, were coded as finding benefit in the experience of being at university. This coding was varied in its coded responses, as the more nebulous notion of university experience could refer to social aspects of university life, engaging in a more inclusive and academic environment unlike that of the respondent's background, or again clarifying what the notion of higher education study entails, as the following response details:

I made industry contacts, won awards for my work, learned to learn at a university level, gain confidence and skills, matured in a safe and structured environment, made friends of many backgrounds and ages, learned a lot, built support networks, lived in a new city, learned who I was, built a life and met many long lasting friends. [\#397]

What is most interesting about this response is the expression of both material and nonmaterial benefits alongside each other, positioning these as of equal value to their overall impression of the benefits of study. Their response gives an indication of the plethora of beneficial aspects related to the experience of university as a base from which pathways between social networks, industry connections and learning platforms all interconnect.

Responses from this category were not uniformly positive. As with 'clarifying experience' responses, those who found university was not to their liking were coded throughout this category. There were those who indicated that although they found the content interesting, the mode of study was not particularly beneficial to them, or was better approached later in life:

Leaving the degree allowed me to really understand that University wasn't just a natural progression from High School, but something to be undertaken seriously, and required a greater level of dedication from myself. [\#350]

A more nuanced understanding of success through higher education would be to recognise that whether positive or negative, there is likely to be some benefit from university participation, such as the respondent who wrote:

It gave me the opportunity/push to live in another city which broadened my horizons and my experience of living out of home. It helped me realise that your idea of what something will be and the reality can be misaligned and that that is okay. It's better to try and realise it's not for you than have this dream of something sitting in the back of your mind for the rest of your life; I can say I put myself out there and tried something. It also gave me confidence in my abilities as a creative that I was able to get into the highly competitive degree. 
There were many benefits, some of which have helped over the last decade, some are manifesting now, and I have no doubt that knowledge I gained during the degree and experience because of it will continue to positively impact my life into the future. [\#235]

\section{Critical analysis of higher education 'success' policy and practice}

Despite plenty of scholarship on retention and success, research rarely frames the outcomes for non-completers as anything other than negative. Often the discourse surrounding these students refers to them as 'drop-outs' (Habel et al., 2016; Norton \& Cherastidtham, 2018) and positions their incomplete study as failure (McCormack, 2005), which fails to recognise the complex nature of students' lives and the changing patterns of participation in higher education in a mass participatory system (Gale \& Tranter, 2011; Pitman, 2014). As we have observed, this is likely due in part to the fact that these students are notoriously difficult to find once they have disengaged from university, let alone reach out to in order to gather useful research data (Habel et al., 2016). Without research seeking out and considering the perspective of students who leave university before completing, the nature of success in higher education is reduced to a onedimensional notion of completion versus failure (Harvey \& Szalkowicz, 2016; McCormack, 2005).

This is particularly problematic because, as Smit notes, 'deficit thinking produces and (eventually) reproduces these differences between students' (2012, p. 372). As such, without adequate feedback regarding beneficial elements of university participation beyond metrics associated with course completion, universities are likely to fail to realise and build upon the strength of university participation. Consequently, there will be an ongoing tendency to identify groups of students by their lack of normative capital and the perception of this as inherently negative and in need of correction (Burke, Bennett, Burgess, Gray, \& Southgate, 2016; Smit, 2012).

Policies focused on highlighting the benefits of full completion (Committee on Education and Labor, 2019; Higher Education Standards Panel, 2017) might seem, theoretically, to reject the notion that students are the problem. This is because they imply institutions are either communicatively (in the form of misleading marketing and exaggerated benefits of the value of a degree) or procedurally (in terms of low teaching/course quality and poor value for money) deficient in their teaching practice. However, whilst these policies might seek to address structural issues which undermine efforts to improve retention and completion rates, they tend to ignore the lived experience of students by perpetuating the same, one-dimensional definition of success (Harvey \& Szalkowicz, 2016; O'Shea \& Delahunty, 2018). Whilst it is necessary to avoid supposing certain students are deficient and in need of 
improvement to participate in and complete university studies, there still exists a level of deficit thinking in the presumption that completion of university is the sole means of achieving equitable social progress.

This is not to suggest that the current, dominant discourse of higher education success is invalid. However, the case for plurality is increasingly being made (e.g., Harvey \& Szalkowicz, 2016; O'Shea \& Delahunty, 2018; Smit, 2012), and our own study further reinforces that alternative conceptualisations of success demands further attention in higher education policy and practice. O'Shea and Delahunty suggest that based on the Capability Approach of Amartya Sen, 'success can be more broadly conceived as reflecting a person's achievement $[\ldots]$ as outputs and outcomes that are regarded as being important and beneficial to themselves' (2018, p. 1064). Success may constitute brief exposure to clarify perceptions of occupational pathways, or it may consist of multiple years of skill acquisition and mastery. Beyond this, successful participation could mean a student is better able to understand the higher education system through personal experience, thus enabling them to pass that knowledge on to their peers or charges, as is reflected in a number of studies engaging with first-in-family research (see, for e.g., King, Luzeckyj, McCann, \& Graham, 2015; O'Shea \& Delahunty, 2018; Wainwright \& Watts, 2019). The key here is that the existing evaluative framework as it relates to higher education may not have the flexibility to reflect such a broad scope of successful achievement in higher education.

Whether those suggested to be deficient are students from disadvantaged backgrounds or those lacking academic rigour, another consequence of deficitcentric policy discourses of participation and completion is an evaluative framework more deeply concerned with understanding the reasons for leaving university than the potential benefits of doing so prior to completion. Reasons for leaving tend to be deeply personal, and the circumstances for discontinuing can be highly variable and difficult for individual students to prepare for. Each student has their own reason as to why they are unable to continue with university studies, however, there are common barriers presented within the complex, monolithic structures of modern higher education institutions.

In a similar manner to the subjectivity of reasons for leaving, the benefits felt by a student who discontinues study are likely to be individually dependent and can be difficult to accurately categorise on a number of levels. Unlike reasons for leaving university, there is no survey of students' perceived benefits with which to compare results (Norton \& Cherastidtham, 2018). Here, the Grattan Institute developed the following categories for assessing benefits of study:

- It helped clarify my career goals

- It taught me useful skills 
- It was interesting

- I made lasting friendships/connections .

- Attending university helped me get employed.

These categories are somewhat problematic. Three out of five options are focused primarily on employment outcomes. Though two of the options consider non-occupational benefits - 'it was interesting' and 'I made lasting friendships/connections' - these reasons for attending university are not likely to be perceived as productive reasons for attending and finding benefit from university, particularly in a context where the purpose of education is to improve employment outcomes (Department for Education, 2017; Higher Education Standards Panel, 2017). This is particularly the case for the broad statement of 'it was interesting'; out of 643 respondents, 331 selected 'it was interesting', yet only 120 selected 'the course didn't interest me' in the following survey question detailing reasons for leaving (Norton \& Cherastidtham, 2018, p. 59). Whilst it is possible almost 200 respondents found university neither interesting nor disinteresting, and some paradoxically selected both, it is curious to see such a large gap between these two options. Incidentally, this could indicate many have avoided selecting 'it was interesting' given the focus on occupational benefits present in most other options for benefits of study.

Further problematising the presentation of options in this survey, the only other option for expressing non-occupationally focused benefits was, paradoxically, 'no benefit'. The substantial number of respondents selecting 'no benefit' when asked whether there were any benefits of study, then in the following open-ended response detailing some sort of benefit that was not articulated amongst the available options, highlights the need for a broader range of options. It is understandable from a neoliberal policy perspective that the survey might focus on occupational benefits, as the purpose of facilitating higher education participation is often framed as a means to improve economic productivity (Connell, 2013). However, it undermines the reliability of the data if respondents select an option such as 'it helped clarify my career goals', then go on to describe such clarification as relating to their field of study interest, not their career goal.

This inherently leads to the problematic notion of success or failure in higher education being a binary set of outcomes, as if surveys continue to frame successful participation in higher education as experiencing material employment benefits from partial completion, it will likely be difficult to comparatively assess results over time. Whilst providing a binary choice between benefits or no benefits prior to a list of options might be a reductive approach to eliciting a more accurate indication of how many students truly 
experienced no beneficial outcomes, if beneficial aspects or non-beneficial aspects were presented as sub-options following selection of either 'benefit' or 'no benefit', this could encourage survey respondents to be more reflective and deliberate in their responses. Additionally, if respondents are presented explicitly with diverse examples of beneficial outcomes upon selecting 'benefits' - such as 'it was interesting' alongside 'it helped me get employed' - it could remove the ambiguity and negative framing of the former option.

The categories presented in the Grattan survey on the whole tend to collapse complex ranges of benefits of study into few categories with relatively particular (and potentially exclusionary) wording. Compounding this issue, the non-specific benefits are limited in scope compared to the options for expressing reasons for leaving university, raising the potential for unrepresentative data if respondents select the closest available option despite not identifying with it entirely, or even select 'no benefit' due to the absence of a representative option. Previous studies, particularly in disability research, have shown in the absence of specific options for common responses, many respondents will opt for an 'other' response, which can hide critical detail in response data (Kent, 2016, p. 148).

\section{Conclusion}

This study assessed data from a unique survey of university non-completers that looked at their own perceptions of the benefits of university engagement without completion, and the factors contributing to their 'dropping out' of higher education. The response rate for open-ended responses providing further detail were markedly high in this survey, which is suspected to be due in part to the rarity of occasions for students who have incomplete degrees to provide feedback to the higher education sector. It is likely that this in particular could be responsible for the rate of response and detail to questions of barriers to completion, as despite their experiences many of the respondents spoke of their continued belief that university, and education in general, are of utmost importance.

Accordingly, this article's analysis of the benefits to partial completion has shown that in students' own estimations, higher education provides many benefits to individuals prior to attainment of a bachelor qualification. Modern universities are far more than lecture halls and silent library floors; campuses are often teeming with opportunities for extracurricular engagement, clubs, student associations and other social spaces, which provides plenty of opportunities for students to network, make new friends and develop a broader understanding of the world around them. Careers centres and work-in-learning placement units can provide a 'foot in the door' for those looking to experience 
firsthand what the careers they are studying for will be like, and provide the opportunity for students to demonstrate their capabilities directly to employers without the need for a signalling qualification.

Further to this, the findings of this article indicate higher education participation is critical for clarifying the next steps for a student, following completion of secondary school, or a decision to pursue a particular career path. For some, the ability to access higher education in Australia with little upfront financial burden is critical for allowing students to make an informed decision as to whether university or a certain career is the right path for them at that point in their life. The opportunity to clarify what university study is like and to achieve a level of personal growth through the experience of attending university was by far the most prominent theme of this analysis. If the role of higher education in the future is to involve the facilitation of intermittent engagement with formal and informal streams of education for all individuals regardless of their background, there needs to be room for successful university participation to constitute more than just completion and related employment. Such findings should be of great benefit to social justicecentric equity research, which seeks to emphasise this very point.

Furthermore, there need to be more options to articulate benefits related to occupational entry and engagement experienced by non-completers beside 'attending university helped me get employed'. The intention behind an option worded as such is clearly identifiable by survey participants, which raises the potential for students who have left with a negative experience of university to reject the notion that their time at university played any role in their future career path. A limited range of questions targeting aspects of occupation benefits articulated in the results of this study - such as providing them with a valuable or unique occupational skillset rather than general 'useful skills', or by providing experience of a field linked to their eventual occupation - could elicit more representative responses, which are less subject to an individual's bias against higher education institutions.

Throughout this article's analysis, it was often clear that the benefits to partial completion were far broader than employment outcomes. Many of these broader benefits are critical for intergenerational rectification of systemic disadvantage, as even an increased understanding of university structures as well as ensuring that a former student's children are not the first in their family to attend university can be of immense benefit to future generations (King et al., 2015; Wainwright \& Watts, 2019).

This is even more important if research is to be done seeking out students who have disengaged from higher education without completing, given the inherent difficulty in reaching these students in meaningful numbers. Students rarely drop out because they 'never wanted a degree' or found 'study was too 
hard' in the absence of mitigating factors, and such deficit-centric assumptions concerning student attrition can limit the relevancy of data collection.

As a result, the findings of this study challenge a binary notion of success and failure in higher education, which emphasises a deficit-centric approach to assessing retention and success. Successful engagement in higher education should not be limited to indicators of attainment of qualifications and a linear progression model of secondary education to higher education to employment.

\section{Note}

1. The Australian Government introduced HECS (Higher Education Contribution Scheme) in 1988 to replace fully subsidised university tuition with a government-student cocontribution system which provided funding for students' share of tuition fees in the form of an incomecontingent loan to be repaid upon graduation and subsequent employment earning over a determined threshold.

\section{Acknowledgements}

The authors would like to thank Andrew Norton and William Mackey at the Grattan Institute for their generosity in sharing the data collected for this analysis, and providing clarifying detail on the details of their survey. We would also like to extend our thanks to all the respondents who took the time to complete the Grattan Institute's survey, and provided such rich comments to consider for this analysis.

\section{Disclosure statement}

No potential conflict of interest was reported by the authors.

\section{Funding}

This work was supported by the Australian Government Research Training Program (RTP) Scholarship. 


\section{References}

Bradley, D., Noonan, P., Nugent, H., \& Scales, B. (2008). Review of Australian Higher Education: (Bradley Report). Canberra: AGPS.

Burke, P. J., Bennett, A., Burgess, C., Gray, K., \& Southgate, E. (2016). Capability, belonging and equity in higher education: Developing inclusive approaches. Bentley: National Centre for Student Equity in Higher Education, Curtin University.

Cahalan, M., Perna, L., The Pell Institute, \& PennAHEAD. (2015). Indicators of higher education equity in the United States: 45 Year Trend Report, 60. Retrieved from http://www. luminafoundation.org/resources/indicators-of-higher-education-equity-in-the-united-states

Committee on Education and Labor. (2019). Don't Stop Believin' (in the value of a college degree). Washington, DC: Author.

Connell, R. (2013). The neoliberal cascade and education: An essay on the market agenda and its consequences. Critical Studies in Education, 54(2), 99-112. doi:10.1080/17508487.2013.776990

Cribb, A., \& Gewirtz, S. (2013). The hollowed-out university? A critical analysis of changing institutional and academic norms in UK higher education. Discourse, 34(3), 338-350. doi:10.1080/ 01596306.2012.717188

Department for Education. (2017). Unlocking talent, fulfilling potential. London: Department for Education, UK Government.

Department of Education and Training. (2018). 2017 equity Peformance data. Canberra: Author.

Fairclough, N. (1993). Critical discourse analysis and the marketization of public discourse: The universities. Discourse \& Society, 4(2), 133-168. doi:10.1177/0957926593004002002

Ford, D. Y., \& Grantham, T. C. (2003). Providing access for culturally diverse gifted students: From deficit to dynamic thinking. Theory Into Practice, 42(3), 217-225. doi:10.1207/ s15430421tip4203

Gale, T., \& Tranter, D. (2011). Social justice in Australian higher education policy: An historical and conceptual account of student participation. Critical Studies in Education, 52(1), 29-46. doi:10. 1080/17508487.2011.536511

Habel, C., Whitman, K., \& Stokes, J. (2016). Exploring the experiences of low-SES students via enabling pathways. Perth: National Centre for Student Equity in Higher Education, Curtin University.

Harper, S. R. (2012). Black male student success in higher education: A report from the national black male college achievement study. Philadelphia, PA: University of Pennsylvania, Center for the Study of Race and Equity in Education.

Harvey, A., \& Szalkowicz, G. (2016). Developing multiple exit pathways within undergraduate courses. International Studies in Widening Participation, 3(1), 52-67.

Higher Education Standards Panel. (2017). Improving retention, completion and success in higher education. Canberra: Department of Education and Training. Retrieved from http://apo.org. au/system/files/175811/apo-nid175811-796616.pdf

Kent, M. (2016). Access and barriers to online education for people with Disabilities. Perth: National Centre for Student Equity in Higher Education, Curtin University.

King, S., Luzeckyj, A., McCann, B., \& Graham, C. (2015). Exploring the experience of being first in family at university. Bentley: National Centre for Student Equity in Higher Education, Curtin University.

Liu, A. (2011). Unraveling the myth of meritocracy within the context of US higher education. Higher Education, 62(4), 383-397. doi:10.1007/s10734-010-9394-7

Liu, K., \& Guo, F. (2016). A review on critical discourse analysis. Theory and Practice in Language Studies, 6(5), 1076-1084.

Lockyer, S. (2004). Coding qualitative data. In M. S. Lewis-Beck, A. Bryman, \& T. F. Liao (Eds.), The SAGE encyclopedia of social science research methods (pp. 137-138). London: Sage.

Marks, G. (2007). Completing university: Characteristics and outcomes of completing and noncompleting students. Longitudinal Surveys of Australian Youth Research Reports: 55, Camberwell, Victoria. 
McCormack, C. (2005). Is non-completion a failure or a new beginning? Research noncompletion from a student's perspective. Higher Education Research \& Development, 24(3), 233-247. doi:10. 1080/07294360500153968

Meyer, H.-D., St. John, E. P., Chankseliani, M., \& Uribe, L. (2013). Fairness in access to higher education in a global perspective. Rotterdam: Sense Publishers.

Norton, A., \& Cherastidtham, I. (2018). Dropping out: The benefits and costs of trying university. Melbourne: Grattan Institute.

O'Keefe, M., Laven, G., \& Burgess, T. (2011). Student non-completion of an undergraduate degree: Wrong program selection or part of a career plan? Higher Education Research \& Development, 30 (2), 165-177. doi:10.1080/07294360.2010.512630

O'Shea, S., \& Delahunty, J. (2018). Getting through the day and still having a smile on my face! How do students define success in the university learning environment? Higher Education Research \& Development, 37(5), 1062-1075. doi:10.1080/07294360.2018.1463973

Pitman, T. (2014). Reinterpreting higher education quality in response to policies of mass education: The Australian experience. Quality in Higher Education, 20(3), 348-363. doi:10.1080/ 13538322.2014.957944

Pitman, T., Koshy, P., \& Phillimore, J. (2015). Does accelerating access to higher education lower its quality? The Australian experience. Higher Education Research \& Development, 34(3), 609623. doi:10.1080/07294360.2014.973385

Pitman, T., Roberts, L., Bennett, D., \& Richardson, S. (2019). An Australian study of graduate outcomes for disadvantaged students. Journal of Further and Higher Education, 43(1), 45-57. doi:10. 1080/0309877X.2017.1349895

Reeves, R. V., \& Howard, K. (2013). The glass floor: Education, downward mobility, and opportunity hoarding. Center on children and families at Brookings.

Smit, R. (2012). Towards a clearer understanding of student disadvantage in higher education: Problematising deficit thinking. Higher Education Research \& Development, 31(3), 369-380. doi:10.1080/07294360.2011.634383

Thomas, L. (2002). Student retention in higher education: The role of institutional habitus. Journal of Education Policy, 17(4), 423-442. doi:10.1080/02680930210140257

Universities UK. (2016). Working in partnership: Enabling social mobility in higher education. London: Author. Retrieved from http://www.universitiesuk.ac.uk/policy-and-analysis/reports/ Documents/2016/working-in-partnership-final.pdf

Wainwright, E., \& Watts, M. (2019). Social mobility in the slipstream: First-generation students' narratives of university participation and family. Educational Review, 1-17. doi:10.1080/ 00131911.2019 .1566209

Wodak, R. (2019). What CDA is about - A summary of its history, important concepts and its developments. In R. Wodak, \& M. Meyer (Eds.), Methods of critical discourse analysis (pp. 112). London: Sage. 